\title{
Isolation of diterpenoids from sugi wood-drying byproducts and their bioactivities
}

\author{
Maiko Tsujimura ${ }^{1,2}$, Manami Goto ${ }^{3}$, Minori Tsuji ${ }^{3}$, Yoshie Yamaji ${ }^{3}$, Tatsuya Ashitani ${ }^{2,4}$, Ken-ichi Kimura ${ }^{2,3}$, \\ Tatsuro Ohira ${ }^{5}$ and Hisayoshi Kofujita ${ }^{2,3^{*}}$
}

\begin{abstract}
Diterpenoids are the main components of the byproducts discharged from sugi wood-drying process (BWP), making BWP a source of these useful compounds. Since there is no method for purifying these compounds from BWP, we sought to develop one. In this study, seven diterpenoids compounds were isolated: abietatriene (I), phyllocladenes (II-i and II-ii; a complex of isophyllocladene and phyllocladene), abietadiene (III), sandaracopimarinal (IV), 6,7-dehydroferruginol (V), ferruginol (VI), and sandaracopimarinol (VII) using medium-pressure liquid chromatography (MPLC) and high-performance liquid chromatography (HPLC). We tested the biological activities of these diterpenoids. Compounds $V$ and VI showed antioxidant activity in the DPPH radical scavenging method, $\beta$-carotene bleaching method, and linoleic acid method. Furthermore, compounds V-VII showed antimicrobial activity against Propionibacterium acnes, and III, VI, and VII showed antifungal activity against Trichophyton mentagrophytes and Trichophyton rubrum. These results contribute to the accumulation of knowledge on diterpenoids and will help in developing new ways of utilizing BWP, a currently unused woody biomass.
\end{abstract}

Keywords: Cryptomeria japonica, Terpenoids, Biological activities

\section{Introduction}

Recently, due to environmental protection efforts in Southeast Asia and changes in the price of wood on the world market, domestic conifer woods have become the main materials for plywood veneer sheets in the Japanese wood industry, replacing imported lumber such as lauan. In plywood factories, green veneer sheets are dried in a boiler at around $170{ }^{\circ} \mathrm{C}$. Because the exhaust steam from the drying process contains a large amount of volatile organic compounds, it is collected by cooling to avoid its release outdoors. After collecting this exhaust steam, a viscous tar-like sediment is also collected, especially from conifer woods like Cryptomeria japonica (sugi), which has a rich resin. Ohira reported that 50 tons of sediment discharged during the drying process is collected per year [1]. Therefore, development of a way to utilize these byproducts is urgently needed.

\footnotetext{
*Correspondence: kofujita@iwate-u.ac.jp

${ }^{2}$ The United Graduate School of Agricultural Science, Iwate University,

18-8 Ueda 3-chome, Morioka, Iwate 020-8550, Japan

Full list of author information is available at the end of the article
}

Our previous studies demonstrated that the main components of the byproducts discharged from sugi wood-drying process (BWP) are diterpenoids, such as ferruginol and sandaracopimarinol [1], and it could remove nitrogen dioxide when they come into contact with nitrogen dioxide gas [1]. BWP also exhibited the antimicrobial activity [2].

We also analyzed the composition of the main diterpene components [3], which in order of abundance were sandaracopimarinol, ferruginol, 6,7-dehydroferruginol, abietadiene, and sandaracopimarinal.

These diterpene compounds have many known bioactivities. For example, sandaracopimarinol has antimicrobial activity [4] and termiticidal activity [5]. Ferruginol has antimicrobial activity $[4,6]$, antioxidant activity [7], gastroprotective and ulcer healing effects [8], termite resistance effects [9], and growth inhibition activity against Heterosigma akashiwo [10]. Moreover, there is a combined inhibitory effect of sandaracopimarinol and ferruginol on shiitake (Lentinula edodes) mycelial growth [11]. 6,7-Dehydroferruginol, which is a derivative of ferruginol, also shows antimicrobial activity [12]. 
Abietadiene can remove nitrogen dioxide upon contact with nitrogen dioxide gas [1] and affects human electroencephalograms when the subjects smelled the compound that dissolved in ethanol by a filter paper [13]. Thus, since BWP is a source of useful compounds, the aims of this study were to accumulate knowledge about the functions of these terpenoids that will help in developing new ways of utilizing BWP and to give them added value.

In this study, seven diterpenoids compounds were isolated from BWP: abietatriene (I), phyllocladenes (phyllocladane (II-i) and isophyllocladene (II-ii)), abietadiene (III), sandaracopimarinal (IV), 6,7-dehydroferruginol (V), ferruginol (VI), and sandaracopimarinol (VII). In our previous report [3], these compounds in BWP are already identified. Then, we examined their antioxidant, antibacterial and antifungal activities to estimate the practical availability. Particularly, the application as the antioxidant for lipid and the therapeutic drug for skin diseases was discussed in this study.

\section{Materials and methods Test microorganisms}

Propionibacterium acnes (NBRC 107605), Trichophyton mentagrophytes (NBRC 6174), and Trichophyton rubrum (NBRC 5467) were ordered from the National Institute of Technology and Evaluation (NITE, Kisarazu, Japan). Culture conditions are described below.

\section{Chemicals}

Palladium-activated carbon $(10 \% \quad \mathrm{Pd}-\mathrm{C})$, Wakogel C-300HG, butylated hydroxytoluene (BHT), linoleic acid, Tween 40, $\beta$-carotene, methyl linoleate, and miconazole nitrate were obtained from Wako Pure Chemical Industries., Ltd. (Osaka, Japan). Cellulose powder was obtained from Toyo Roshi Kaisha., Ltd. (Tokyo, Japan). Chloroform-d [99.8\% atom\% D, containing 0.03\% (v/v) TMS] was obtained from Sigma-Aldrich (Tokyo, Japan). 1,1-Diphenyl-2-picrylhydrazyl was obtained from Tokyo Chemical Industry Co., Ltd. (Tokyo, Japan). GAM broth was obtained from Nissui Pharmaceutical Co., Ltd. (Tokyo, Japan). Benzalkonium chloride was obtained from MP Biomedicals, LLC (Santa Ana, CA, USA). Peptone was obtained from Nihon Pharmaceutical Co., Ltd. (Tokyo, Japan).

\section{Isolation of diterpenoids}

BWP was distilled by solvent-assisted distillation (SAD) using a method developed in our previous research [3] to obtain a water distillate (WD) fraction and a triethylene glycol distillate (TGD) fraction.

Then, the TGD fraction was separated by mediumpressure liquid chromatography (MPLC) and high-performance liquid chromatography (HPLC) as shown in Fig. 1. The TGD fraction was separated into three fractions by MPLC using a normal phase column (Sepacore Silica, 220 g, BÜCHI, Germany). Toluene was used as a first mobile phase for collecting Fraction 1 and Fraction 2. Then, the mobile phase was changed to ethanol for collecting Fraction 3. The chromatogram was checked by RI Monitor RI-10 (EYELA, Tokyo, Japan), Ceramic Pump VSP-3050 (EYELA) was equipped with this fractionation system.

Each collected fraction was evaporated and weighed by drying under reduced pressure. The quantitative analysis was done by gas chromatography with flame ionization detection (GC-FID), and the chemical composition of each collected fraction was confirmed by gas chromatography-mass spectrometry (GC-MS). The analysis conditions of GC-FID and GC-MS are written in the later passage.

Based on GC-FID and GC-MS analyses, compounds I, II-i, II-ii, and III were contained in Fr. 1; compounds IV, V and VI were in Fr. 2; and compound VII was in Fr. 3. The eluted fractions were further fractionated by HPLC using a reversed-phase column (Inertsil ODS-3 $20 \mathrm{~mm}$ i.d. $\times 250 \mathrm{~mm}$, GL Science, Tokyo, Japan), a Shimadzu Liquid Chromatograph LC-6AD pump (Shimadzu, Kyoto, Japan), and a Shodex RI-72 (Showa Denko K.K., Tokyo, Japan) or Shimadzu SPD-20A (UV) detector (Shimadzu). The isolation scheme of diterpenoids from TGD fraction is shown in Fig. 1.

The collected fractions were evaporated and dried under reduced pressure. Then, the yield of each compound (based on the TGD fraction) was calculated as I (0.48\%), II-i and II-ii (0.33\%), III (1.0\%), IV (0.6\%), V (0.59\%), VI (1.8\%), and VII (3.2\%). The analysis and confirmation of the chemical composition of each purified fraction were carried out by GC-FID and GC-MS using an HP-5 column. Finally, ${ }^{1} \mathrm{H}$ and ${ }^{13} \mathrm{C}$ NMR were used for identification of the isolated diterpenoids.

\section{Reduction of sandaracopimarinal (IV) and 6,7-dehydroferruginol (V)}

Because there are no detailed data about NMR analysis for IV and V in literature, we confirmed the structure of IV and V by reduction; IV and V was changed to VII and VI, respectively. The condition of each reaction was written in the following passage.

\section{Sandaracopimarinal (IV)}

Isolated compound IV $(27.4 \mathrm{mg})$ was dissolved in methanol, then $\mathrm{NaBH}_{4}$ was added gradually (total amount of $\mathrm{NaBH}_{4}, 611.4 \mathrm{mg}$ ). After the reaction, the solution (methanol; $20 \mathrm{ml}$ ) was mixed with $n$-hexane $(50 \mathrm{ml})$ and purified water $(30 \mathrm{ml})$, and then the organic phase was collected. The 


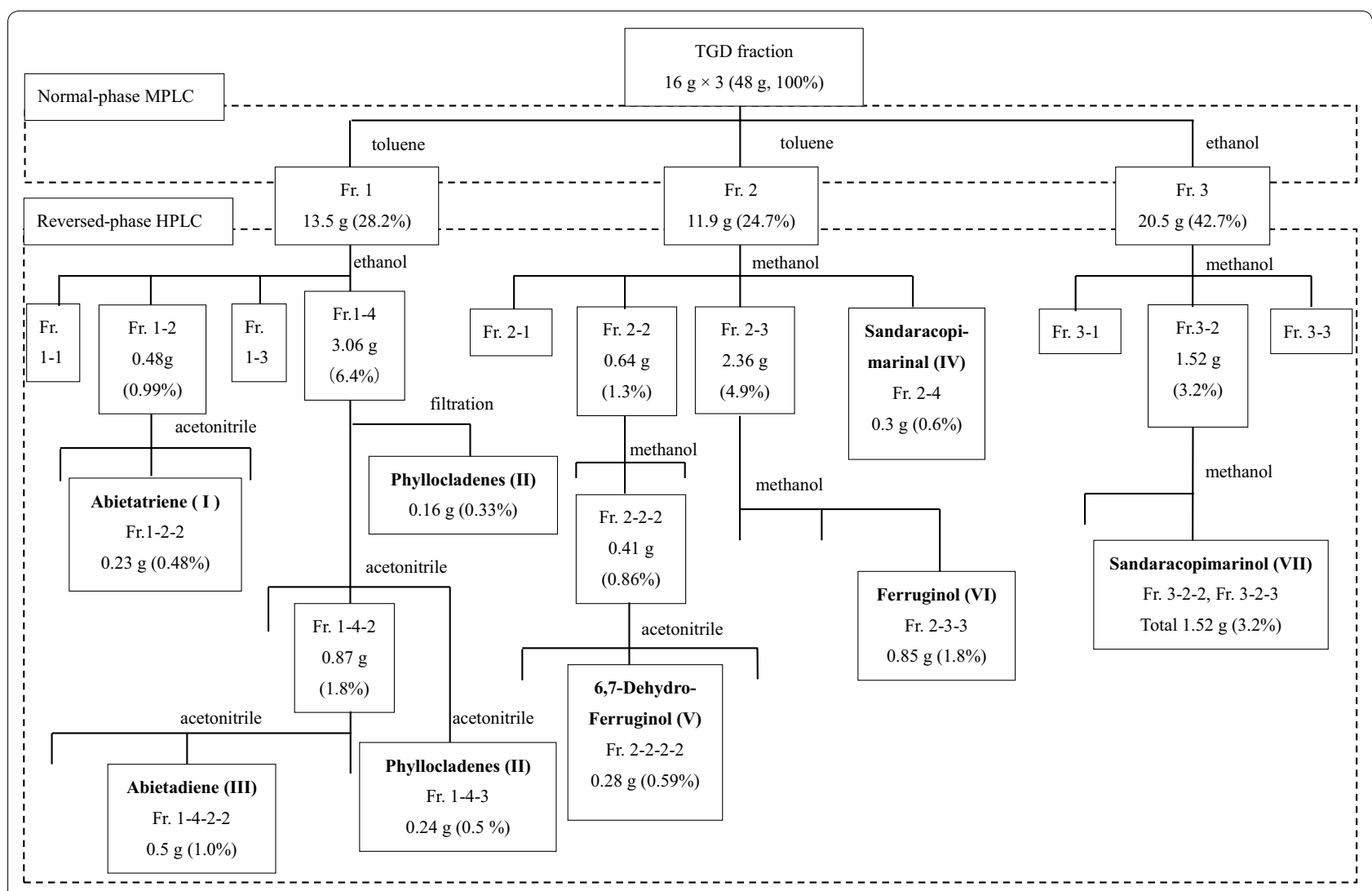

Fig. 1 Isolation scheme of diterpenoids from the triethylene glycol distillates (TGD) fraction

organic phase was dried under reduced pressure. The quantity collected was $20.9 \mathrm{mg}$, and the yield was $76.3 \%$.

\section{6,7-Dehydroferruginol (V)}

According to our previous report [3], isolated compound V (35.0 mg) was dissolved in ethyl acetate and $10 \% \mathrm{Pd}-\mathrm{C}(14.0 \mathrm{mg})$ was added. The gas phase used in this study was $\mathrm{H}_{2}$, and the reaction was done under room temperature. The reaction product was filtered under reduced pressure using a separation funnel containing cellulose powder (40-100 mesh) and Wakogel C-300HG $(40-60 \mu \mathrm{m})$. Then, the filtrate was concentrated and dried under reduced pressure. The quantity collected was $30.9 \mathrm{mg}$, and the yield was $88.3 \%$.

\section{Antioxidant activity}

\section{1,1-Diphenyl-2-picrylhydrazyl (DPPH) radical scavenging} activity [14], with some modifications

Each diterpenoid sample was dissolved in ethanol at a concentration of $10 \mathrm{mM}$. BHT was used as a positive control. A $0.2 \mathrm{ml}$ aliquot of sample solution, $1.0 \mathrm{ml}$ $0.2 \mathrm{M} \mathrm{DPPH}, 0.2 \mathrm{ml} \mathrm{0.1} \mathrm{M} \mathrm{Tris-} \mathrm{HCl}$ (pH 7.4), and $0.6 \mathrm{ml}$ ethanol were mixed in a screw-cap tube. The tubes were shaken and the contents allowed to react at room temperature in the dark. After $30 \mathrm{~min}$, the absorbance was measured at $517 \mathrm{~nm}$ by a UV mini- 1240 spectrophotometer (Shimadzu, Japan).

\section{$\beta$-carotene bleaching assay [15]}

$60 \mu \mathrm{l}$ of each sample solution (5 $\mathrm{mM}$ in dichloromethane) or dichloromethane (control), and $2940 \mu \mathrm{l}$ of an emulsion of linoleic acid, $\beta$-carotene and Tween 40 in sodium phosphate buffer $(\mathrm{pH}$ 6.8) were collected in an opaque screw-cap tube and mixed well. Each sample was then incubated at $50{ }^{\circ} \mathrm{C}$, and the absorbance measured at $470 \mathrm{~nm}$ by a UV-mini 1240 spectrophotometer after 0 , $15,30,45,75,105,135,165$, and $195 \mathrm{~min}$.

\section{Linoleic acid method [16], with some modifications}

$150 \mu \mathrm{l}$ methyl linoleate solution $(0.05 \mathrm{mM}$ in ethyl acetate) and $100 \mu \mathrm{l}$ of each sample $\left(1 \times 10^{-3} \mathrm{mM} ; 2 \% \mathrm{~mol}\right.$ equivalent weight of methyl linoleate) were mixed in a $4 \mathrm{ml}$ vial. After removing ethyl acetate, the vials were heated at $85^{\circ} \mathrm{C}$ in an oven. Heating time was set to 0,6 , 12 , and $24 \mathrm{~h}$. After heating, the vials were cooled in a desiccator. Then, $1.2 \mathrm{ml}$ ethyl acetate was poured into each vial. Samples were analyzed by GC-FID to calculate the 
residual rate of methyl linoleate by the internal standard method using heptadecane as internal standard.

\section{Antibacterial activity against $P$. acnes}

The minimal inhibitory concentration (MIC) and minimal bactericidal concentration (MBC) values were determined for P. acnes (NBRC 107605). P. acnes was preincubated in GAM liquid medium (pH 7.3) at $37^{\circ} \mathrm{C}$ for $72 \mathrm{~h}$ under anaerobic conditions. The number of bacteria was counted by the McFarland turbidimetry method; turbidity corresponded to the No. 5 standard test tube $\left(15 \times 10^{8} / \mathrm{ml}\right)$ [17]. Isolated diterpenoids were dissolved in ethanol, and twofold serial dilutions of each sample from $5 \mathrm{mg} / \mathrm{ml}$ were prepared. Benzalkonium chloride was used as a positive control, and the solution was prepared in the same manner as the isolated terpenoids. To a $50 \mu \mathrm{l}$ aliquot of each sample solution, $10 \mathrm{ml}$ GAM liquid medium was added in a screw-cap test tube and mixed well. The final concentrations of purified diterpenoids and benzalkonium chloride were twofold serial dilutions from $25 \mu \mathrm{g} / \mathrm{ml}$. Then, inoculum was added to each screw-cap test tube $(n=3)$, and the tubes were incubated at $37^{\circ} \mathrm{C}$ for $72 \mathrm{~h}$ under anaerobic conditions. The concentrations showing no visually detectable bacterial growth were determined to be the MIC value. A $1 \mathrm{ml}$ aliquot of the culture medium collected from test tubes with no visually detectable bacterial growth was inoculated in $10 \mathrm{ml}$ of fresh GAM liquid medium. As done for MIC, the concentration at which there was no bacterial growth after incubation was determined to be the MBC.

\section{Antifungal activity against Trichophyton species [18]}

Trichophyton mentagrophytes (NBRC 6174) and T. rubrum (NBRC 5467) were pre-incubated in Sabouraud agar medium ( $\mathrm{pH}$ 6.0) at $25{ }^{\circ} \mathrm{C}$ for about 2 weeks. The concentration of isolated diterpenoids was adjusted to $4 \mathrm{mg} / \mathrm{ml}$ by acetone. Miconazole nitrate (positive control) was prepared twofold serial dilutions from 50 to $3.13 \mu \mathrm{g} / \mathrm{ml}$. Then, $2 \mathrm{ml}$ molten Sabouraud agar medium was poured into a sterilized Petri dish $(35 \mathrm{~mm}$ diameter, Falcon), and $100 \mu \mathrm{l}$ of sample solution was spread on the surface of the medium, for a final concentration of each isolated diterpenoid of $400 \mu \mathrm{g}$, with the miconazole nitrate concentration ranging from 5 to $0.313 \mu \mathrm{g}$. After removing acetone by air-drying, the agar blocks with hyphae on the surface were punched out by a cork borer ( $5 \mathrm{~mm}$ in diameter), and then placed in the center of Petri dishes. The Petri dishes were incubated at $25^{\circ} \mathrm{C}$ for 10 days. The average diameter of hyphae for three test specimens was measured by a caliper, and the area in which mycelia grew $\left(\mathrm{mm}^{2}\right)$ was calculated to evaluate the antifungal activity of test samples.
Area in which mycelia grew

$=($ Total area occupied by mycelia,

calculated from average diameter)

- (Agar block area)

\section{GC-FID}

GC-FID was performed on a 7890B GC System (Agilent Technologies, Santa Clara, CA, USA) equipped with an HP-5 column $(30 \mathrm{~m} \times 0.25 \mathrm{~mm}$ i.d., $0.25 \mu \mathrm{m}$ film thickness, Agilent Technologies). The oven temperature started at $60{ }^{\circ} \mathrm{C}$ and increased at $3.0{ }^{\circ} \mathrm{C} / \mathrm{min}$ to at $240{ }^{\circ} \mathrm{C}$. The temperature of both the injector and the detector was $250{ }^{\circ} \mathrm{C}$. Flame ionization was used for detection. The volume of injected sample was $1 \mu \mathrm{l}$, and the split ratio was 1:4. The carrier gas was $\mathrm{N}_{2}$ and the flow rate was $1.3 \mathrm{ml} / \mathrm{min}$. When we analyzed the mixture, $0.2 \mathrm{mg}$ of heptadecane was added for $10 \mathrm{mg}$ of sample. On the other hand, when pure substance or a few yield samples were analyzed, $1 \mathrm{mg}$ of heptadecane was added to $1 \mathrm{mg}$ of sample. The total volume was adjusted to $1 \mathrm{ml}$ using $n$-hexane or ethyl acetate.

The conditions for the linoleic acid method were an initial oven temperature of $180{ }^{\circ} \mathrm{C}$, which was increased at $10{ }^{\circ} \mathrm{C} / \mathrm{min}$ to at $280{ }^{\circ} \mathrm{C}$. The temperature of both the injector and detector was $280^{\circ} \mathrm{C}$. Other parameters were the same as above.

\section{GC-MS}

GC-MS was performed on a GCMS-QP2010 instrument (Shimadzu) equipped with an HP-5 column. The initial oven temperature was at $60^{\circ} \mathrm{C}$, which increased at $3.0{ }^{\circ} \mathrm{C} /$ $\min$ to $240{ }^{\circ} \mathrm{C}$. The injector and the detector temperatures were both $250{ }^{\circ} \mathrm{C}$. The injected sample volume was $1 \mu \mathrm{l}$ and split rate was 1:40. The carrier gas was $\mathrm{He}$ and the flow rate was $1.61 \mathrm{ml} / \mathrm{min}$. Electron ionization was used and the mass range was from 40 to $500 \mathrm{~m} / \mathrm{z}$. Mass spectra were taken at $70 \mathrm{eV}$ and the ion source temperature was $250{ }^{\circ} \mathrm{C}$. The GC-MS samples were prepared using the same procedure used for GC-FID.

\section{NMR}

NMR spectra $\left({ }^{1} \mathrm{H}: 400 \mathrm{MHz},{ }^{13} \mathrm{C}: 100 \mathrm{MHz}\right)$ were recorded on a JEOL AL400 FT-NMR spectrometer. Each purified diterpenoid $(50 \mathrm{mg}$ ) was dissolved in $0.7 \mathrm{ml}$ chloroform- $d$. The experimentally measured spectra were compared with data from the literature [6, 19-23].

\section{Statistical analysis}

All biological activity tests were performed in triplicate. The results were evaluated by a Tukey-Kramer test, and were expressed as mean \pm standard deviation (SD) for each measurement. The $p$ values were 
set at $<0.05$. Statcel 3 (4 Steps Excel-Statistics, OMS Publishing Ltd, Saitama, Japan) was used as statistical software.

\section{Results and discussion}

Isolation and identification of diterpenoids

From the TGD fraction, seven diterpenoids compounds were isolated by MPLC, and HPLC. We could purify these diterpenoids more easily from the BWP than the plant materials such as wood, branches and leaves, because the content rate of diterpenoids of BWP was higher than that of the plant materials. Furthermore, these diterpenoids were fractionated in the TGD fraction from BWP by SAD.

The yield of each fraction was based on the TGD fraction $(48 \mathrm{~g})$. The structure and purity of each terpenoid were confirmed by NMR. However, there were no NMR data that the ${ }^{13} \mathrm{C}$ signals have been assigned for IV or $\mathrm{V}$ in published reports. Thus, the isolated samples were reduced to form VII and VI, and then identified by ${ }^{1} \mathrm{H}$ and ${ }^{13} \mathrm{C}$ NMR analyses. We also obtained the DEPT, HMBC and HMQC data of IV and V, and assigned the ${ }^{13} \mathrm{C}$ NMR signals based on these data. The chemical shifts of the diterpenoids are in Tables 1 and 2, and the structures of the diterpenoids purified from the TGD fraction are shown in Figs. 2 and 3. These major components of the TGD fraction were all known compounds. In this study, the ${ }^{13} \mathrm{C}$ NMR signals of IV and V were assigned for the first time.

\section{Antioxidant activities}

To investigate the antioxidant activities of the purified terpenoids, three assays, a DPPH radical scavenging
Table $2{ }^{1} \mathrm{H}$ and ${ }^{13} \mathrm{C}$ data for compound IV and compound $\mathrm{V}$ in $\mathrm{CDCl}_{3}-\mathrm{d}$

\begin{tabular}{|c|c|c|c|c|}
\hline \multirow{2}{*}{$\begin{array}{l}\text { Carbon } \\
\text { number }^{a}\end{array}$} & \multicolumn{2}{|l|}{ IV: Sandaracopimarinal } & \multicolumn{2}{|c|}{ V:6,7-Dehydroferruginol } \\
\hline & $\overline{{ }^{1} \mathrm{H}}$ & ${ }^{13} \mathrm{C}$ & ${ }^{1} \mathrm{H}$ & ${ }^{13} \mathrm{C}$ \\
\hline \multirow[t]{2}{*}{1} & $1.08 \mathrm{~s}$ & 38.3 & $1.54 \mathrm{~m}$ & 36.0 \\
\hline & $1.80 \mathrm{~d}(J=4.52)$ & & & \\
\hline 2 & $1.62 \mathrm{~m}$ & 17.4 & $1.69 \operatorname{sept}(J=6.8)$ & 19.0 \\
\hline 3 & $1.28 d(J=6.8)$ & 32.4 & $1.50 \mathrm{~m}$ & 41.0 \\
\hline 4 & & 49.7 & & 32.8 \\
\hline \multirow[t]{2}{*}{5} & $1.55 \mathrm{~d}(J=2.68)$ & 46.8 & $2.05 \mathrm{~m}$ & 51.0 \\
\hline & $1.62 \mathrm{~m}$ & & & \\
\hline 6 & $1.42 \mathrm{~m}$ & 24.7 & $5.87 \mathrm{dd}(J=9.6,2.7)$ & 127.5 \\
\hline \multirow[t]{2}{*}{7} & $2.10 \mathrm{~m}$ & 35.4 & $6.49 \mathrm{dd}(J=9.6,3.0)$ & 127.2 \\
\hline & $2.21 \mathrm{dd}(J=14.2,4.8)$ & & & \\
\hline 8 & & 136.3 & & 126.3 \\
\hline 9 & $1.81 \mathrm{~s}$ & 50.3 & & 147.5 \\
\hline 10 & & 37.2 & & 37.7 \\
\hline 11 & $1.46 \mathrm{~m}$ & 18.6 & $6.57 \mathrm{~s}$ & 109.5 \\
\hline \multirow[t]{2}{*}{12} & $1.36 \mathrm{~m}$ & 34.4 & & 152.2 \\
\hline & $1.51 \mathrm{~m}$ & & & \\
\hline 13 & & 37.4 & & 130.9 \\
\hline 14 & $5.24 \mathrm{~s}$ & 129.5 & $6.88 \mathrm{~s}$ & 124.5 \\
\hline 15 & $5.77 \mathrm{~d}(J=17.2,10.8)$ & 148.7 & $3.16 \operatorname{sept}(J=6.8)$ & 26.7 \\
\hline 16 & $4.90 \mathrm{dd}(J=17.4,10.8)$ & 110.2 & $1.22 \mathrm{~d}(J=6.8)$ & 22.4 \\
\hline 17 & $1.04 \mathrm{~s}$ & 26.0 & $1.26 \mathrm{~d}(J=6.8)$ & 22.5 \\
\hline 18 & $9.23 \mathrm{~s}$ & 206.5 & $0.96 \mathrm{~s}$ & 32.6 \\
\hline 19 & $1.09 \mathrm{~s}$ & 14.6 & $1.04 \mathrm{~s}$ & 22.8 \\
\hline 20 & $0.86 \mathrm{~s}$ & 15.4 & $1.01 \mathrm{~s}$ & 20.1 \\
\hline
\end{tabular}

Compound IV: sandaracopimarinal; compound V: 6,7-dehydroferruginol

a Numbers correspond to the numbers in Fig. 3

Table $1{ }^{13} \mathrm{C}$ chemical shifts of purified diterpenoids from the TGD fraction

\begin{tabular}{|c|c|c|c|c|c|c|c|c|c|c|c|c|c|}
\hline & No. & $C-1$ & & $\mathrm{C}-2$ & $C-3$ & C-4 & $C-5$ & $C-6$ & $\mathrm{C}-7$ & $C-8$ & & $C-9$ & $C-10$ \\
\hline Abietatriene & 1 & 38.9 & & 19.3 & 41.8 & 33.5 & 50.4 & 19.1 & 30.5 & 134.9 & & 147.6 & 37.5 \\
\hline Isophyllocladene & $\|-\mathrm{i}$ & 19.0 & & 18.6 & 42.2 & 33.2 & 56.0 & 20.3 & 37.8 & 47.9 & & 53.3 & 37.3 \\
\hline Phyllocladene & II-ii & 39.5 & & 18.5 & 42.0 & 33.2 & 56.6 & 20.3 & 41.1 & 43.7 & & 57.0 & 37.9 \\
\hline Abietadiene & III & 39.3 & & 18.9 & 42.4 & 34.9 & 50.3 & 24.0 & 121.5 & 135.4 & & 51.0 & 32.9 \\
\hline Ferruginol & VI & 38.8 & & 19.3 & 41.6 & 33.4 & 50.3 & 19.2 & 29.7 & 127.0 & & 148.5 & 37.4 \\
\hline \multirow[t]{2}{*}{ Sandaracopimarinol } & VII & 38.8 & & 18.3 & 34.5 & 37.3 & 47.8 & 22.3 & 35.7 & 136.9 & & 50.5 & 37.7 \\
\hline & No. & $C-11$ & $C-12$ & $C-13$ & $C-14$ & $C-15$ & $C-16$ & $C-17$ & $C-18$ & C-19 & $C-20$ & Refere & nce no. \\
\hline Abietatriene & 1 & 124.3 & 123.8 & 145.4 & 126.8 & 33.4 & 24.0 & 24.0 & 33.3 & 21.6 & 24.9 & {$[19]$} & \\
\hline Isophyllocladene & $\|-i$ & 19.2 & 24.6 & 43.3 & 55.0 & 140.6 & 129.3 & 15.5 & 33.7 & 21.9 & 15.0 & {$[20]$} & \\
\hline Phyllocladene & $\|-\mathrm{ii}$ & 19.0 & 34.0 & 42.7 & 50.4 & 157.6 & 41.5 & 102.3 & 33.7 & 22.0 & 15.1 & {$[21]$} & \\
\hline Abietadiene & III & 22.7 & 27.6 & 144.9 & 122.5 & 34.9 & 21.4 & 21.9 & 33.3 & 20.8 & 13.6 & {$[22]$} & \\
\hline Ferruginol & $\mathrm{VI}$ & 110.9 & 150.8 & 131.5 & 126.5 & 26.7 & 22.5 & 22.7 & 33.3 & 21.5 & 24.7 & {$[6,23]$} & \\
\hline Sandaracopimarinol & VII & 18.7 & 35.4 & 38.1 & 128.6 & 149.0 & 110.0 & 25.9 & 72.1 & 17.9 & 15.5 & {$[6]$} & \\
\hline
\end{tabular}


<smiles>CC(C)c1ccc2c(c1)CC[C@H]1C(C)(C)CCC[C@@]21C</smiles>

I<smiles>CC(C)C1=CC2=CC[C@H]3C(C)(C)CCC[C@]3(C)[C@H]2CC1</smiles><smiles>CC1=C[C@@]23CC[C@H]4C(C)(C)CCC[C@]4(C)[C@]12CCC3C</smiles>

II- $\mathbf{i}$<smiles>C=C1CC[C@H]2[C@H](CC[C@H]3C(C)CCC[C@@]32C)C1</smiles>

II- ii

Fig. 2 The chemical structures of purified diterpenoids from the triethylene glycol distillates (TGD) fraction (I abietadiene, II-i isophyllocladene, II-ii phyllocladene, III abietadiene, $\mathbf{V l}$; ferruginol, VII sandaracopinarinol)
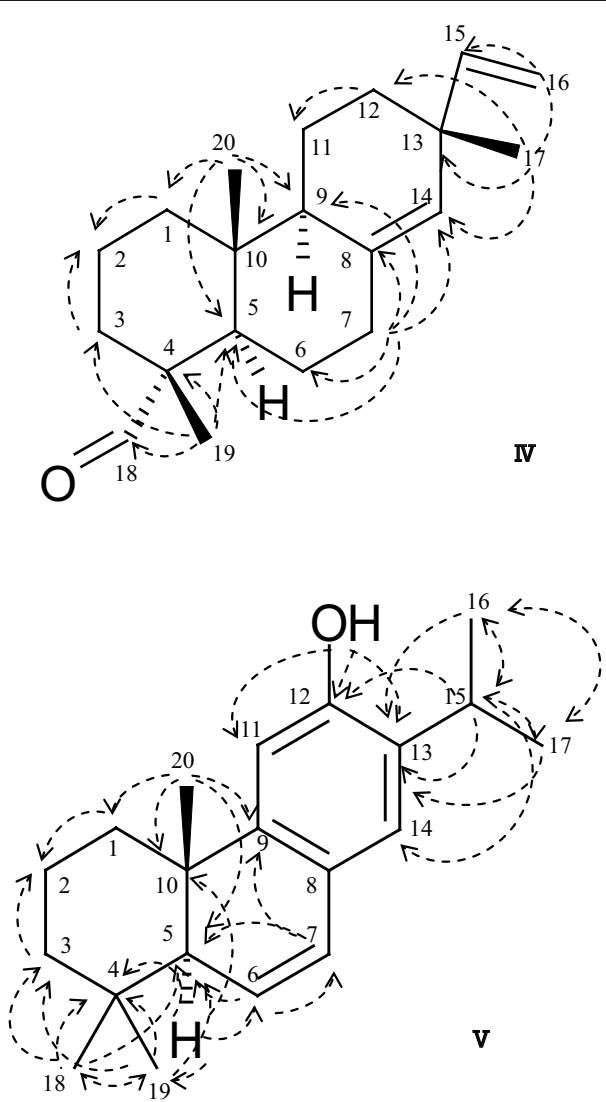

Fig. 3 The chemical structures and the heteronuclear multiple bond correlation (HMBC) correlations observed in the NMR analysis of sandaracopimarinal (IV) and 6,7-dehydroferruginol (V) assay, a $\beta$-carotene bleaching assay and the linoleic acid method, were adopted. BHT was used as the positive control.

\section{DPPH radical scavenging activity}

The results are shown in Fig. 4. The activity of VI was $69.6 \%$. It has already been reported that VI has a radical

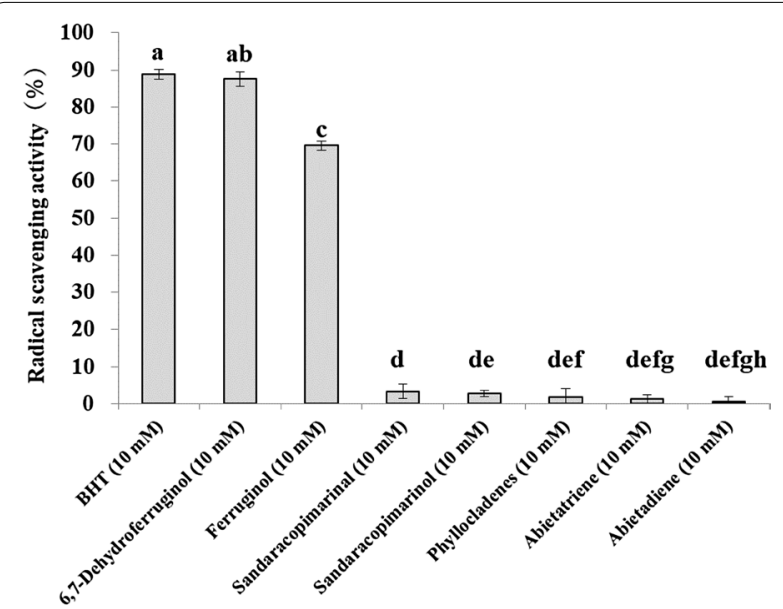

Fig. 4 The 1,1-diphenyl-2-picrylhydrazyl (DPPH) radical scavenging activity of each purified diterpenoids. We adopted butylhydroxytoluene (BHT) as positive control. The sample concentration was $10 \mathrm{mM} . n=3$. Error bars indicate standard deviation. Values with the same letters (a-h) showed no significant differences. Tukey-Kramer test, $p<0.05$ 


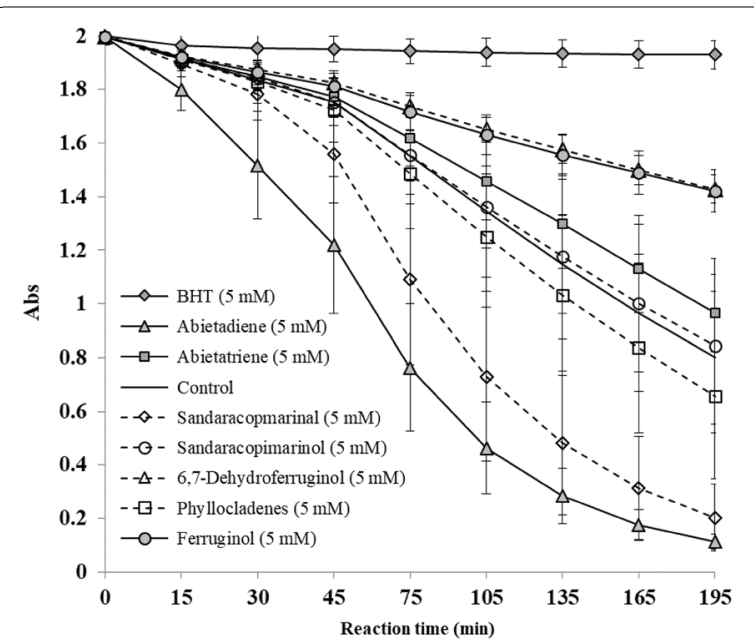

Fig. 5 The antioxidant activity of purified diterpenoids evaluated by the $\beta$-carotene bleaching method. The sample concentration was $5 \mathrm{mM} . n=3$. Error bars indicate standard deviation. Tukey-Kramer test, $p<0.05$

capturing function [7]. Also, it has been reported that VI showed $53 \%$ of inhibition ratio at $100 \mu \mathrm{g} / \mathrm{ml}$, but the activity of VII was less than $10 \%$ at $100 \mu \mathrm{g} / \mathrm{ml}$ in DPPH radical scavenging activity assay [24]. Our results supported this knowledge. The activity of $\mathrm{V}$ was $87.6 \%$ $(10 \mathrm{mM})$, which was comparable of the activity of BHT $(88.8 \%, 10 \mathrm{mM})$. Moreover, though there were no previous data in the literature about the DPPH radical scavenging activity of $\mathrm{V}$, it was stronger than that of VI. However, the other terpenoids did not show any DPPH radical scavenging activity.

\section{$\beta$-Carotene bleaching activity}

The results are shown in Fig. 5. After 195 min of reaction, BHT ( $5 \mathrm{mM})$ maintained high antioxidant activity, inhibiting the bleaching of $\beta$-carotene. Compared with BHT, VI and V (at $5 \mathrm{mM}$ ) showed weak antioxidant activity, with the degree of activity of VI and V almost equal. Other purified terpenoids did not show antioxidant activity. Our results supported those of a previous study [16], in which VI showed antioxidant activity based on a $\beta$-carotene bleaching assay.

\section{Linoleic acid method}

The results are shown in Fig. 6. After $24 \mathrm{~h}$ of heating, BHT maintained high antioxidant activity. Among the purified terpenoids, VI and V had antioxidant activity. After $6 \mathrm{~h}$ of heating, both compounds showed the same activity as BHT. However, their activity weakened slowly, and the amount of methyl linoleate almost disappeared after $24 \mathrm{~h}$ of heating. It may be that the chemical composition of

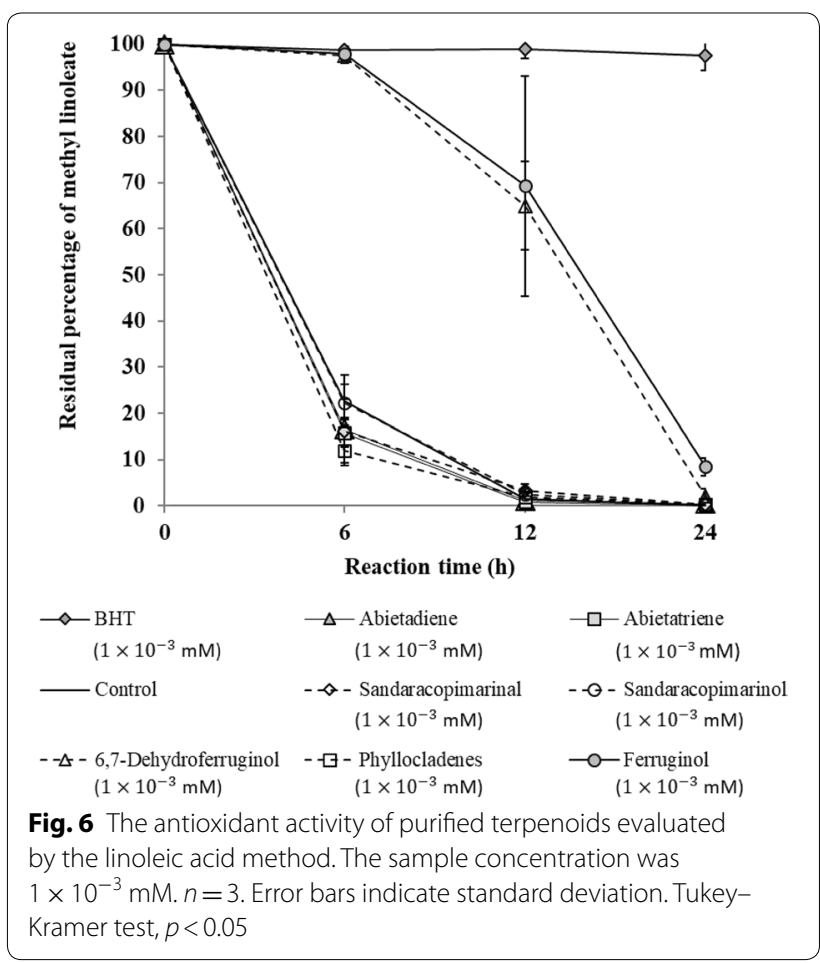

these terpenoids was changed by heating [16]. The relationship between the change in chemical composition and antioxidant activity is not clear; so detailed investigations should be carried out. Other purified terpenoids showed the same tendency as the negative control; so we could not confirm antioxidant activities.

VI and V showed antioxidant activity in every assay. There are literature data for evaluating the bioactivities of 11 essential oils [25]. Based on these results, Thymus vulgaris essential oil, thymol chemotype, shows the highest activities in the DPPH assay and $\beta$-carotene bleaching test. The substructures of VI and V are common to the structure of thymol. We currently consider that the key to their activity is their structure.

\section{Antibacterial and antifungal activities}

In commercial use of terpenoids, mixing them with an ointment is better than a water-based solution like skin lotion because they are hydrophobic compounds. Data are, therefore, needed on how diterpenoids affect microbes that cause skin diseases. Thus, we chose $P$. acnes, T. mentagrophytes and T. rubrum as the test microorganisms because they are epidermal bacteria.

\section{Antibacterial activity against $P$. acnes}

The results are shown in Table 3. The antimicrobial activity against $P$. acnes was evaluated by MIC and MBC values. Benzalkonium chloride was adopted as a positive 
Table 3 The growth inhibition activity of purified diterpenoids against Propionibacterium acnes is shown as MIC and MBC values

\begin{tabular}{lll}
\hline Compound & \multicolumn{2}{l}{ Growth inhibition against P. acnes } \\
\cline { 2 - 3 } & MIC $(\boldsymbol{\mu} \mathbf{g} / \mathbf{m l})$ & MBC $(\boldsymbol{\mu g} / \mathbf{m l})$ \\
\hline Benzalkonium chloride & 1.56 & 3.13 \\
Abietatriene (I) & 6.25 & $25 \leqq$ \\
Phyllocladenes (II) & 12.5 & $25 \leqq$ \\
Abietadiene (III) & 12.5 & $25 \leqq$ \\
Sandaracopimarinal (IV) & 12.5 & $25 \leqq$ \\
6,7-Dehydroferruginol (V) & 3.13 & 6.25 \\
Ferruginol (VI) & 3.13 & 3.13 \\
Sandaracopimarinol (VII) & 6.25 & 12.5
\end{tabular}

Benzalkonium chloride was used as positive control. Cultures and test sections were grown at $37^{\circ} \mathrm{C}$ for $72 \mathrm{~h}$

control. VI, V and VII showed antimicrobial activities based on both MIC and MBC. VI exhibited the strongest activity of the purified terpenoids, and the activity of $\mathrm{V}$, an analog of VI, was the next strongest. VII exhibited the third strongest activity, but IV, an analog of VII, had no detectable $\mathrm{MBC}$ value. There is interest in a patent for treatment of acne that uses the essential oil or the epicubenol and isopropylmethylphenol collected from Japanese cedar wood or barrels [26]. Though the method was not the same as ours, there is, thus, a possibility that terpenoids originating from $C$. japonica may be useful in the treatment of acne. $P$. acnes are anaerobic Gram-positive bacteria. In previous study, ferruginol showed antimicrobial activity toward Gram-positive bacteria [6]. However, the MBC value of the other purified terpenoids (I, II, III, IV) could not be detected.

\section{Antifungal activity against Trichophyton species}

Trichophyton mentagrophytes and T. rubrum were used in this test. The results are shown in Figs. 7 and 8. III, VII, and VI inhibited the fungal growth. Compound III showed the highest growth inhibition, which was stronger than that of oxygen-containing diterpenoids like VI and VII. Interestingly, abietatriene (I) did not show any inhibition, though its structure is similar to that of III: both I and III are hydrocarbon abietane-type diterpene, the A ring structure is common. And V, an analog of VI, and IV, an analog of VII, showed no activity too. Generally, III showed weak bioactivity, such as antimicrobial activity. It was considered that the degree of volatility and the difference in permeability of these compounds in agar medium affected the growth of Trichophyton species. A previous study reported that essential oils have antiTrichophyton activity, and it was found that essential oils show antimicrobial activity according to a process: first

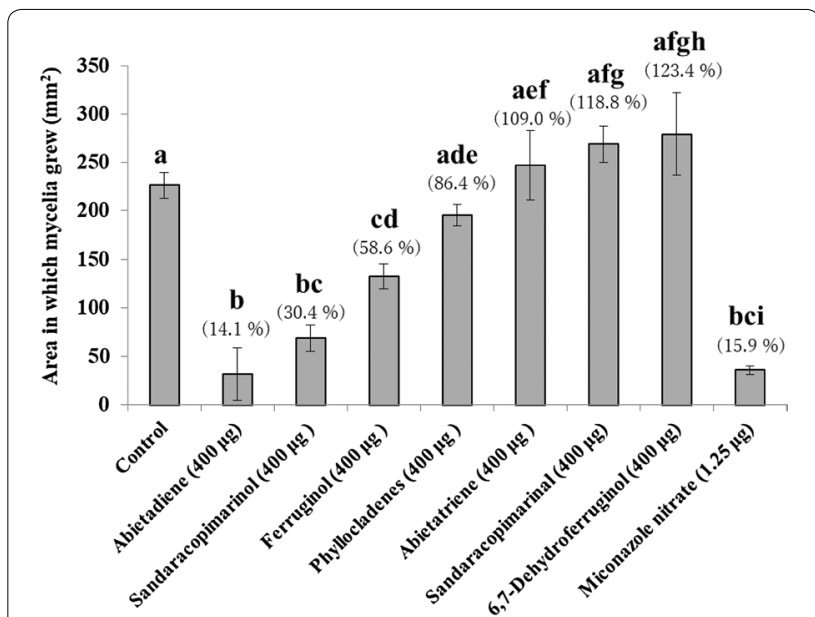

Fig. 7 The growth inhibitory activity of purified diterpenoids for Trichophyton mentagrophytes. $n=3$. Error bars indicate standard deviation. Values with the same letters (a-i) showed no significant differences. Tukey-Kramer test, $p<0.05$. The ratio of each test section's area in which mycelia grew for that of control was written on this graph

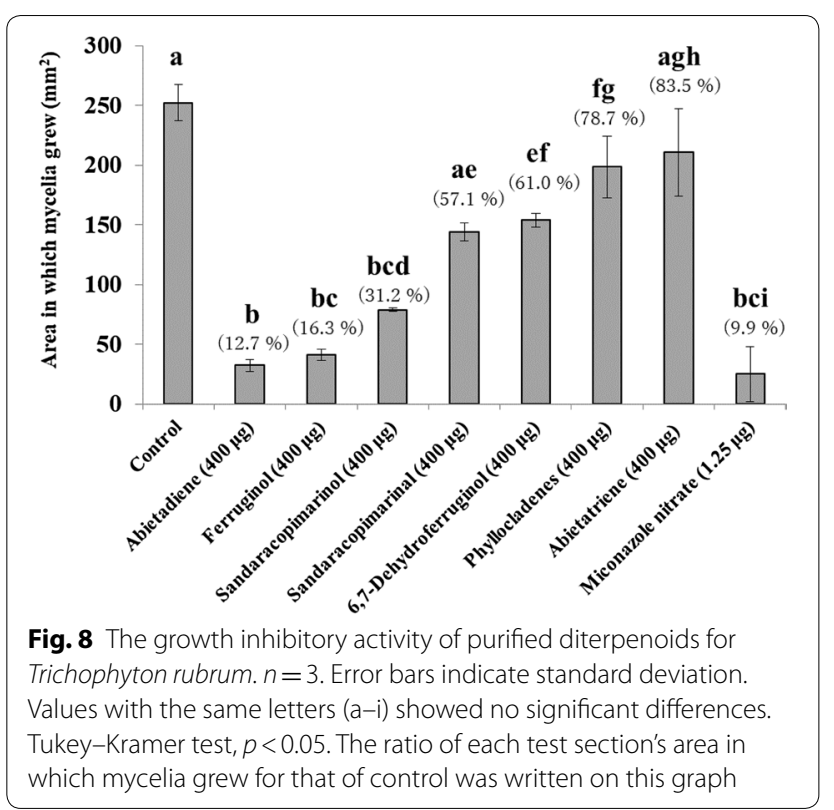

they volatilize and diffuse in the air, and then they are absorbed by the agar medium [27]. In that study [27], the essential oil compounds that were used as experimental materials were mainly monoterpenoids and sesquiterpenoids. The behavior of diterpenoids was not the same as that of monoterpenoids or sesquiterpenoids, but it could be that the volatility of compounds affects their antimicrobial activity. Also, it was considered that the structure of diterpenoids could have been modified over the 10-day incubation term. In any case, the reason for changes in 
activity over time was not clear; so we would like to consider this subject for future analysis.

\section{Conclusions}

Seven diterpenoids compounds were isolated: I, II, III, IV, $\mathrm{V}, \mathrm{VI}$, and VII, from the TGD fraction collected by SAD using BWP as the raw material. We also tried to measure several kinds of assays to investigate each potency of purified diterpenoids. From these results, V and VI were showed antioxidant activity using the three antioxidant assays. Then, VI, V, and VII showed antimicrobial activity to $P$. acnes. And III, VI, and VII showed growth inhibition activity toward T. mentagrophytes and T. rubrum. These results indicate the potentials of the diterpenoids as the antioxidant for lipid and the therapeutic drug for skin diseases. This study has contributed to accumulation of knowledge about diterpenoids derived from C. japonica and to expansion of the possibilities for development of the practical uses for BWP.

\begin{abstract}
Authors' contributions
HK designed and integrated this study. MG, Minori Tsuji and YY performed the purification of diterpenoids and each NMR analysis. Maiko Tsujimura performed the purification and the assays for biological activities, collated these results. TA gave the accurate advices for handling and evaluating about terpenoids. KK gave the accurate advices for the assays that we tried in this study. TO have carried out the previous study about sugi wood-drying byproducts, and contributed in the purification of terpenoids as well as the assays for biological activities. Maiko Tsujimura prepared and revised the manuscript. All authors read and approved the final manuscript.
\end{abstract}

\section{Author details \\ 1 Institute of Wood Technology, Akita Prefectural University, 11-1 Kaieizaka, Noshiro, Akita 016-0876, Japan. ${ }^{2}$ The United Graduate School of Agricultural Science, Iwate University, 18-8 Ueda 3-chome, Morioka, Iwate 020-8550, Japan. ${ }^{3}$ Faculty of Agriculture, Iwate University, 18-8 Ueda 3-chome, Morioka, I wate 020-8550, Japan. ${ }^{4}$ Faculty of Agriculture, Yamagata University, 1-23 Wakaba-machi, Tsuruoka, Yamagata 997-8555, Japan. ${ }^{5}$ Forestry and Forest Products Research Institute (FFPRI), 1, Matsunosato, Tsukuba, Ibaraki 305-8687, Japan.}

\section{Acknowledgements}

We are very grateful to Associate prof. Koji Harashina, Faculty of Agriculture, Iwate University, for giving advice on statistical analysis.

This study was presented at the 67th Annual Meeting of the Japan Wood Research Society, Nagoya, Japan, March, 27-29, 2016.

\section{Competing interests}

The authors declare that they have no competing interests.

\section{Publisher's Note}

Springer Nature remains neutral with regard to jurisdictional claims in published maps and institutional affiliations.

Received: 21 May 2018 Accepted: 21 December 2018

Published online: 03 April 2019

\section{References}

1. Ohira T (2014) Removal of nitrogen dioxide using woody plant constituents. Aroma Res 15:162-169 (in Japanese)
2. Ohira T (2009) Efficient utilisation of condensed water discharged from wood-drying processes. J Jpn Assoc Odor Environ 40:400-411 (in Japanese)

3. Tsujimura M, Tsuji M, Kofujita H, Ohira T (2015) New separation method for terpenoids in byproducts discharged during sugi wood-drying process, and purification of ferruginol. J Wood Sci 61:308-315

4. Matsushita Y, Hwang YH, Sugamoto K, Matsui T (2006) Antimicrobial activity of heartwood components of sugi (Cryptomeria japonica) against several fungi and bacteria. J Wood Sci 52:552-556

5. Sogabe A, Kinjyo K, Abe F, Yamauchi T, Yaga S (2000) Termiticidal substances from the heartwood of Cryptomeria japonica D. Don. Mokuzai Gakkaishi 46:124-131 (in Japanese)

6. Li WH, Chang ST, Chang SC, Chang HT (2008) Isolation of antibacterial diterpenoids from Cryptomeria japonica bark. Nat Prod Res 22:1085-1093

7. Wang SY, Wu JH, Shyur LF, Kuo TH, Chang ST (2002) Antioxidant activity of abietane-type diterpenes from heartwood of Taiwania cryptomerioides Hayata. Holzforschung 56:487-492

8. Rodríguez JA, Theoduloz C, Yáñez T, Becerra J, Schmeda-Hirschmann G (2006) Gastroprotective and ulcer healing effect of ferruginol in mice and rats: assessment of its mechanism of action using in vitro models. Life Sci 78:2503-2509

9. Kano H, Shibutani S, Hayashi K, lijima Y, Doi S (2004) Effect of hightemperature drying processes on termite resistance of sugi (Cryptomeria japonica) heartwood. Mokuzai Gakkaishi 50:91-98 (in Japanese)

10. Saijo H, Tsuruta K, Kusumoto N, Ashitani T, Takahashi K (2013) Growth inhibition activities of Sugi bark components against Heterosigma akashiwo. J Wood Sci 59:238-242

11. Matsui T, Matsushita Y, Sugamoto K, Ogawa K, Komiyama A, Muta S (2001) Mycelial growth inhibition of shiitake (Lentinula edodes) by several terpenoids isolated from sugi (Cryptomeria japonica) wood. Mokuzai Gakkaishi 47:58-62 (in Japanese)

12. Kusumoto N, Ashitani T, Murayama T, Ogiyama K, Takahashi K (2010) Antifungal abietane-type diterpenes from the cones of Taxodium distichum rich. J Chem Ecol 36:1381-1386

13. Sakamaki S, Kofujita H, Sugawara M (2013) Effect of odors from Cryptomeria japonica essential oils on human electroencephalogram. Aroma Res 14:64-71 (in Japanese)

14. Shimamura T, Matsuura R, Tokuda T, Sugimoto N, Yamazaki S, Matsufuji H, Matsui T, Matsumoto K, Ukeda H (2007) Comparison of conventional antioxidants assays for evaluating potencies of natural antioxidants as food additives by collaborative study. Nippon Shokuhin Kagaku Kogaku Kaishi 54:482-487 (in Japanese)

15. Mikami I, Tsushida T (2007) The evaluation manual of food function, no. 2; a subsidized project of The Ministry of Agriculture, Forestry and Fisheries. The Japanese Society for Food Science and Technology, pp 87-92 (in Japanese)

16. Saijo H, Kofujita H, Takahashi K, Ashitani T (2015) Antioxidant activity and mechanism of the abietane-type diterpene ferruginol. Nat Prod Res 29:1739-1743

17. Member of the Inst. of Medical Sci., The Univ. of Tokyo student's union (1998) The outline of microbiology experiment, 2nd edn. Maruzen Publishing Co. Ltd, Tokyo, pp 59-60 (in Japanese)

18. Kofujita H, Fujino Y, Ota M, Takahashi K (2006) Antifungal diterpenoids from the bark of Cryptomeria japonica D. Don. Holzforshung 60:20-23

19. Miguel Del Corral JM, Gordaliza M, Salinero MA, Sanfeliciano A (1994) ${ }^{13} \mathrm{C}$ NMR data for abieta-8, 11, 13-triene diterpenoids. Magn Reson Chem 32:774-781

20. Tsuruta K, Yoshida Y, Kusumoto N, Sekine N, Ashitani T, Takahashi K (2011) Inhibition activity of essential oils obtained from Japanese trees against Skeletonema costatum. J Wood Sci 57:520-525

21. Duc DKM, Fetizon M, Lazare S, Grant PK, Nicholls MJ, Liau HTL, Francis MJ, Poisson J, Bernassau JM, Roque NF, Wovkulich PM, Wenkert E (1981) ${ }^{13} \mathrm{C}$ NMR spectroscopy of tetracarbocyclic diterpenes and related substances. Tetrahedron 37:2371-2374

22. San Feliciano A, Miguel del Corral JM, Goldaliza M, Salinero MA (1993) ${ }^{13}$ C NMR data for abieta-7,13-diene diterpenoids. Magn Reson Chem 31:841-844

23. Tezuka Y, Kasimu R, Li JX, Basnet P, Tanaka K, Namba T, Kadota S (1998) Constituents of roots of Salvia deserta SCHANG (Xinjiang-Danshen). Chem Pharm Bull 46:107-112 
24. Cheng SS, Chang ST (2014) Bioactivity and characterization of exudates from Cryptomeria japonica bark. Wood Sci Technol 48:831-840

25. Sacchetti G, Maietti S, Muzzoli M, Scaglianti M, Manfredini S, Radice M, Bruni R (2005) Comparative evaluation of 11 essential oils of different origin as functional antioxidants, antiradicals and antimicrobials in foods. Food Chem 91:621-632

26. Takao Y, Yamada T, Mizoguchi H (2012) Anti-propionibacterium acnes composition containing epicubenol. Jpn Kokai Tokkyo Koho JP2012241012 A
27. Inouye S, Uchida K, Maruyama N, Yamaguchi H, Abe S (2006) A novel method to estimate the contribution of the vapor activity of essential oils in agar diffusion assay. Jpn J Med Mycol 47:91-98

\section{Submit your manuscript to a SpringerOpen ${ }^{\circ}$ journal and benefit from:}

- Convenient online submission

- Rigorous peer review

- Open access: articles freely available online

- High visibility within the field

- Retaining the copyright to your article

Submit your next manuscript at $\boldsymbol{\sim}$ springeropen.com 